\title{
Bioaccessibility and arsenic speciation in carrots, beets and quinoa from a contaminated area of Chile
}

\author{
I. Pizarro ${ }^{1}$, M. Gómez-Gómez ${ }^{2}$, D. Román ${ }^{2}$ \& M.A. Palacios ${ }^{2}$ \\ ${ }^{1}$ Facultad de Ciencias Básicas, Universidad de Antofagasta, Antofagasta, Chile \\ ${ }^{2}$ Department of Analytical Chemistry, Faculty of Chemistry, Universidad Complutense de Madrid, Madrid, Spain
}

\begin{abstract}
The study is focused on locally-grown, such as carrots, beets and quinoa from the As-polluted $\mathrm{Chiu}$ Chiu area in Northern Chile. For the vegetables, were investigated: i) Their total $\mathrm{As}, \mathrm{Cu}, \mathrm{Pb}, \mathrm{Cr}, \mathrm{Cd}$ and $\mathrm{Mn}$ content ii) Arsenic speciation by LC-ICPMS analysis; iii) Arsenic bioaccessibility iv) Arsenic species present in the extracts and v) Arsenic dietary exposure. In vitro gastrointestinal digestion of As from carrots and beets, whereas efficiency was about $40 \%$ for quinoa. For carrots, only As(III) and As(V) species were found, being their concentration levels similar. In the case of quinoa, around $85 \%$ of the element was present as $\mathrm{As}(\mathrm{V})$.
\end{abstract}

\section{INTRODUCTION}

The Northern Chilean economy has been mainly supported by the exploitation of copper mining resources and mineral smelting plants. Arsenic can be present in minerals, associated with copper and other heavy metals. In addition, the Loa river water is also naturally contaminated by As. The concentration of As in the water of the Loa hydrographic basin changes dramatically over the course of the river. Assessment of the contribution to human diet of As and other contaminant elements in food requires studying not only their total element content but also their absorption rates in the gastrointestinal tract (Khouzam et al., 2011; Pizarro et al., 2003). A way to evaluate the absorbable fraction in trace element bioaccessibility studies is the "in vitro" simulation of the digestion process.

\section{METHODS/EXPERIMENTAL}

\subsection{Materials and methods}

An ICPMS, (HP-4500, Agilent Technologies, Analytical System, Tokyo, Japan) operating under normal multi-element tuning conditions was used for total arsenic and other metals analysis. For arsenic speciation, an ICPMS has been used as detector system after LC species separation. Chilean vegetable samples were collected from 3 different places of the Chiu Chiu Chilean area. Carrots and beets were peeled with a plastic knife and the edible part was treated in a titanium blender until a homogeneous mash was achieved. A fraction of about $2 \mathrm{~kg}$ of flesh were lyophilized. For sample mineralization, about $0.5 \mathrm{~g}$ of the vegetables was digested in PTFE vessels with $5 \mathrm{~mL}$ of concentrated $\mathrm{HNO}_{3}$ and $2 \mathrm{~mL}$ of $\mathrm{H}_{2} \mathrm{O}_{2}$.

\subsection{Extraction procedures and in vitro digestion}

For arsenic speciation by LC-ICPMS, two extraction procedures have been employed: Methanol: water $(1: 1)$ and enzymatic protease-lipase extraction. Arsenic species were identified in the different extracts. Samples were digested following a laboratory-simulated three-step digestion process: Salivary digestion, about $1.0 \mathrm{~g}$ of lyophilized sample was mixed with $5 \mathrm{~mL}$ of salivary juice. Gastric digestion, $10 \mathrm{~mL}$ of the prepared gastric juice was added to the solid fraction after salivary digestion and intestinal digestion, $10 \mathrm{~mL}$ of the prepared intestinal juice was added to the solid fraction obtained in the gastric digestion.

\section{RESULTS AND DISCUSSION}

\subsection{As and $\mathrm{Cr}, \mathrm{Cu}, \mathrm{Mn}, \mathrm{Pb}$ and $\mathrm{Cd}$ analysis in carrots, beets and quinoa}

When vegetables are grown in contaminated soils, the bioavailable fraction of the elements present in the soil may migrate to the vegetable through intake mechanisms where microorganisms and the vegetal physiology are frequently involved.

Table 1 shows the concentrations of $\mathrm{As}, \mathrm{Cd}, \mathrm{Cu}$, $\mathrm{Pb}, \mathrm{Mn}$ and $\mathrm{Cr}$ in the lyophilized flesh of carrots, beets and in dried quinoa growing in the Chiu Chiu area; the concentrations of the same elements in local vegetables from Spain; and the metal concentration ratios between Chilean and Spanish samples. The concentrations of all tested elements in the Spanish samples fall within those levels reported for uncontaminated vegetables. The arsenic concentrations found in lyophilized carrots, beets and quinoa were 0.52 , 
Table 1. Total As, Cd, $\mathrm{Pb}, \mathrm{Cu}, \mathrm{Mn}$ and $\mathrm{Cr}$ content in Chilean and Spanish lyophilized vegetables. Results expressed in $\mathrm{mg} \mathrm{kg}^{-1}$.

\begin{tabular}{|c|c|c|c|c|c|c|}
\hline \multicolumn{2}{|c|}{ Vegetables } & \multirow{2}{*}{$\begin{array}{c}\text { As } \\
0,52=0.04\end{array}$} & \multirow{2}{*}{$\frac{C d}{0,05=0,01}$} & \multirow{2}{*}{$\begin{array}{c}\mathrm{Pb} \\
0,12=0,02\end{array}$} & \multirow{2}{*}{$\begin{array}{c}\mathrm{Cu} \\
7,75=0,91\end{array}$} & \multirow{2}{*}{$\begin{array}{c}\text { Mn } \\
4,75=0,51\end{array}$} \\
\hline & Flesh-C & & & & & \\
\hline Carrots & $\begin{array}{l}\text { Flesh-S } \\
\text { Factor }\end{array}$ & $0,02=0,01$ & $\begin{array}{c}0.07=0,01 \\
0.7\end{array}$ & $\begin{array}{c}0.09=0,01 \\
1.3\end{array}$ & $\begin{array}{c}s, 82=0,59 \\
0.9\end{array}$ & $2,28=0,18$ \\
\hline & Peel-C & $1,62=0,02$ & $0,08=0.01$ & $0,21=0.02$ & $16,3=1,5$ & $9,95=0,20$ \\
\hline & Peel -S & $0,15=0,01$ & $0,12=0,02$ & $0,23=0,03$ & & $13,7=0,9$ \\
\hline & Factor & 11 & 0.7 & 0.9 & 0.9 & 0.7 \\
\hline \multirow{6}{*}{ Beets } & Flesh-C & $0,62=0.05$ & $0,09=0,00$ & $0,36=0,01$ & $6,71=0,95$ & $8,38=0.16$ \\
\hline & Flesh-S & $0,02=0,00$ & $0.05=0,00$ & $<$ LD & $3,82 \pm 2,1$ & $3,84=0,16$ \\
\hline & Factor & 26 & 1.8 & $(0,006)$ & 1,7 & 2,2 \\
\hline & & $3,20=0,06$ & $0,11=0,01$ & $0,31=0,05$ & $28,6=0,5$ & $21,8=0,2$ \\
\hline & Peel-S & $\begin{array}{l}0,22=0,01 \\
0,020\end{array}$ & $0,03=0,01$ & $<$ LD & $3,8=1,2$ & $11,1=0,3$ \\
\hline & Factor & 14 & 3,6 & $(0,008)$ & 7 & 2 \\
\hline & & $0,20=0,02$ & $0,38=0,07$ & $0,04=0,02$ & $7,89=0,73$ & $13,5=2,4$ \\
\hline Quinoa -S & & $0.01=0,01$ & $\angle D$ & $0,09=0,01$ & $1,14=0,16$ & $4,11=0,11$ \\
\hline Factor & & 20 & .. & 0,4 & 7 & 3 \\
\hline
\end{tabular}

C: Chilean; S: Spanish. Factor: Metal concentration in Chilean/Spanish samples.

0.62 and $0.20 \mathrm{mg} \mathrm{kg}^{-1}$, respectively. The most studied vegetable, the As concentration permitted by the Codex Alimentarious is $0.3 \mathrm{mg} \mathrm{kg}^{-1}$ for total As and $0.2 \mathrm{mg} \mathrm{kg}^{-1}$ of inorganic As. The WHO recommendation for rice is a limit of $1.0 \mathrm{mg} \mathrm{As} \mathrm{kg}{ }^{-1}$. Chile has established a maximum of $0.5 \mathrm{mg} \mathrm{As} \mathrm{kg}{ }^{-1}$ for cereals. Therefore, the concentration found in the analyzed vegetables did not greatly exceed those levels allowed by the Chilean law.

Previous studies performed a decade ago in carrots growing in the same area showed total As levels around $50 \mathrm{mg} \mathrm{kg}^{-1}$, a hundred times higher than those obtained nowadays soil cleaning and water decontamination treatments carried out nowadays, could be responsible for the decreasing trend found. The methodology employed for the analysis of most of the elements has been validated with CRMs of vegetables.

\subsection{Arsenic speciation in carrots, beets and quinoa}

In carrots, only inorganic As(III) and As(V) species were found, at similar concentration levels. For quinoa, $82 \%$ of the As was present as $\mathrm{As}(\mathrm{V})$, being about $15 \%$ as As(III). No other species were found in the water: methanol (1:1) fraction for both vegetables. Terrestrial plants in general are known to present very low efficiency mechanisms of biomethylation. Probably the contamination of these soils makes it difficult for soil microorganisms to develop biomethylation mechanisms that might produce methylated species available for absorption through the vegetables roots. Beets showed a different behavior, with inorganic $\mathrm{As}(\mathrm{V})$ (about 20\%) and several unknown As species (representing about $70 \%$ of the total As), with retention time of $4.5 \mathrm{~min}$, being present (data not shown). Sucrose is the sugar extracted from beets; therefore Assucrose by-products might be the unidentified species. The results obtained in the present study, show a lack of methylated species probably due to the lower arsenic concentration than that previously found. However, the proportion of $\mathrm{As}(\mathrm{III})$ and $\mathrm{As}(\mathrm{V})$ species are in a similar range.
Table 2. Bioaccessibility of As in the digestion process of Chilean samples by ICP-MS.

\begin{tabular}{|c|c|c|c|c|c|c|}
\hline \multicolumn{2}{|c|}{ Vegetables } & \multirow{2}{*}{$\begin{array}{c}\text { As } \\
0,52=0.04\end{array}$} & \multirow{2}{*}{$\begin{array}{c}\mathrm{Cd} \\
0,05=0,01\end{array}$} & \multirow{2}{*}{$\begin{array}{c}\mathrm{Pb} \\
0,12=0,02\end{array}$} & \multirow{2}{*}{$\begin{array}{c}\mathrm{Cu} \\
7,75=0,91\end{array}$} & \multirow{2}{*}{$\begin{array}{c}\mathrm{Mn} \\
4,75=0,51\end{array}$} \\
\hline & Flesh-C & & & & & \\
\hline Carrots & $\begin{array}{l}\text { Flesh-S } \\
\text { Factor }\end{array}$ & $\begin{array}{l}0,02=0,01 \\
24\end{array}$ & $\begin{array}{c}0.07=0,01 \\
0.7\end{array}$ & $\begin{array}{c}0.09=0,01 \\
1.3\end{array}$ & $\begin{array}{c}\$, 82=0,59 \\
0.9\end{array}$ & \\
\hline \multirow{9}{*}{ Beets } & Peel-C & $1,62=0,02$ & $0,08=0.01$ & $0,21=0.02$ & $16,3=1,5$ & $9,95=0,20$ \\
\hline & Peel -S & $0,15=0,01$ & $0,12=0,02$ & $0,23=0,03$ & $17,3=0,9$ & $13,7=0,9$ \\
\hline & Factor & 11 & & 0.9 & 0.9 & \\
\hline & Flesh-C & $0,62=0.05$ & $0,09=0,00$ & $0,36=0,01$ & $6,71=0,95$ & $8,38=0.16$ \\
\hline & Flesh-s & $0,02=0,00$ & $0.05=0,00$ & $<\mathrm{LD}$ & $3,82=2,1$ & $3,84=0,16$ \\
\hline & Factor & 26 & 1.8 & $(0,006)$ & 1,7 & \\
\hline & Peel-C & $3,20=0,06$ & $0,11=0,01$ & $0,31=0,05$ & $28,6=0,5$ & $21,8=0,2$ \\
\hline & Peel-S & $0,22=0,01$ & $0,03=0,01$ & & $3,8=1,2$ & $11,1=0,3$ \\
\hline & Factor & 14 & 3,6 & $(0,008)$ & 7 & 2 \\
\hline Quinoa - $C$ & & $0,20=0,02$ & $0,38=0,07$ & $0,04=0,02$ & $7,89=0,73$ & $13,5=2,4$ \\
\hline Quinoa -S & & $0.01=0,01$ & $\angle D$ & $0,09=0,01$ & $1,14=0,16$ & $4,11=0,11$ \\
\hline Factor & & 20 & .. & 0,4 & 7 & 3 \\
\hline
\end{tabular}

Results expressed in lyophilized vegetables $(n=3)$.

\subsection{Bioaccessibility of As in carrots, beets and quinoa}

Compared to in vivo studies, the in vitro sequential gastrointestinal fluid extraction is a relatively simple, yet effective approach to estimate the bioaccessibility of dietary arsenic. Table 2 shows: the total As concentrations in the different extracts of the in vitro gastrointestinal digestion process.

No significant transformation of the original As species found in the methanolic or enzymatic solutions seems to take place during "in vitro" gastrointestinal digestion of the vegetables.

\section{CONCLUSIONS}

Inorganic $\mathrm{As}(\mathrm{III})$ and $\mathrm{As}(\mathrm{V})$ were the only species present in carrots and quinoa. Regarding the toxicological risk, quinoa is the vegetable to be able to accumulate the highest amount of inorganic As, but its bioaccessibility is only about $40 \%$. On the contrary, for carrots and beets the As bioaccessibility is about $100 \%$. However, since the main As species present in beets are probably arsenosugars, presumably less toxic.

\section{ACKNOWLEDGEMENTS}

The authors thank Universidad Complutense de Madrid, Spain (007/ 11 VIII-2011 (S2013/ABI-3028), the European FEDER program and the project MECESUP U.A., Chile, for financial support.

\section{REFERENCES}

Khouzam, R.B., Pohl, P. \& Lobinski, R. 2011. Bioaccessibility of essential elements from white cheese, bread, fruit and vegetables. Talanta 30(86):425-428.

Pizarro, I., Gómez, M., Cámara, C. \& Palacios, M.A. 2003. Arsenic speciation in environmental and biological samples. Extraction and stability studies. Anal. Chim. Acta 495(1-2): 85-98. 